\title{
Long term outcomes of small pigmented choroidal melanoma treated with primary photodynamic therapy
}

Kelsey A. Roelofs MD FRCSC ${ }^{1}$

Ido Didi Fabian MD ${ }^{1,2}$

Amit K. Arora, MBBS, MRCOphth ${ }^{1,3}$

Victoria M.L. Cohen MA Cantab, MB, BChir, FRCOphth ${ }^{1,3}$

Mandeep S. Sagoo MB, PhD, FRCS (Ed), FRCOphth ${ }^{1,3}$

${ }^{1}$ Ocular Oncology Service, Moorfields Eye Hospital, London, United Kingdom

${ }^{2}$ Goldschleger Eye Institute, Sheba Medical Center, Tel-Hashomer, Tel-Aviv University, TelAviv, Israel

${ }^{3}$ NIHR Biomedical Research Centre for Ophthalmology at Moorfields Eye Hospital and University College London Institute of Ophthalmology, London, United Kingdom

Running title: PDT for small pigmented choroidal melanoma

Meeting Presentation: We have submitted this abstract to the AAO annual meeting.

Corresponding Author: $\quad$ Professor Mandeep Sagoo

Moorfields Eye Hospital NHS Foundation Trust, 162 City Road, London, EC1V 2PD

Tel: 02072533411

Email: m.sagoo@ucl.ac.uk

No financial support was received for this research. None of the authors have any financial dislcosures or conflicts of interest to declare. This manuscript has not previously been submitted for publication.

The research was supported by the National Institute for Health Research (NIHR) Biomedical Research Centre based at Moorfields Eye Hospital NHS Foundation Trust and UCL Institute of Ophthalmology. The views expressed are those of the author(s) and not necessarily those of the NHS, the NIHR or the Department of Health.
Abstract word count: 338 words Manuscript word count: 3256 
37 Keywords: photodynamic therapy, verteporfin, choroidal melanoma 
38 PRECIS: Treatment of small, pigmented, posterior choroidal melanomas using PDT with 39 verteporfin preserves visual acuity; however, 5-year treatment success is only $38.4 \%$. Recurrence 40 most commonly occurred along the tumor edges, often with minimal increase in thickness. 
41 ABSTRACT:

Purpose: To report the long-term outcomes of patients with small, pigmented posteriorly located choroidal melanoma undergoing primary treatment using photodynamic therapy (PDT) with verteporfin at the London Ocular Oncology Service.

Design: Retrospective interventional consecutive case series

Subjects: All patients undergoing primary treatment using PDT with verteporfin from April 2014 and December 2015 and followed until December 2019.

Methods: This is a long-term follow up study of the same cohort of patients previously reported by our group in 2017 and 2018.

Main Outcome Measure: Local tumor control, visual outcomes and metastasis-free survival.

Results: Twenty-six patients were included with a mean ( \pm SD) age and tumour thickness of 62 \pm 14 years and $1.3 \pm 0.5 \mathrm{~mm}$, respectively. Tumours were posteriorly located (mean distance to optic nerve and fovea $=2.0 \pm 2.2$ and $1.6 \pm 1.5 \mathrm{~mm}$, respectively) and the majority were fully pigmented (73\%). Overall, patients were followed for a median [IQR, range] of 49.5 [15.3, $7.0-$ 66.0] months from first PDT to last follow up. Over the course of this study, 14/26 (54\%) have developed a local recurrence at a median of 20.0 months [20.5, 4.7-60.9 months]. The most common pattern of recurrence was an isolated increase in basal dimensions $(9 / 14 ; 64 \%)$. Median [IQR] final LogMAR visual acuity of the whole cohort was 0.2 [0.5]. The only statistically significant difference in baseline and outcome characteristics between treatment failures and non-failures was distance to fovea (median [IQR]: 0.5 [1.3] versus 2.5 [2.8]; $\mathrm{P}=0.002$ ) and final LogMAR visual acuity (median [IQR]: 0.50 [0.80] versus 0.00 [0.14]; P-value $=0.002$ ), respectively.

Conclusions: While treatment of small pigmented posterior choroidal melanoma with PDT effectively preserves visual acuity, five-year treatment-success calculated by Kaplan-Meier analysis was only $38.4 \%$. Recurrences after PDT tend to occur along the tumor edges, often with minimal increase in thickness. Given the substantial risk of treatment failure, primary PDT with

74 vertepofrin is recommended in exceptional cases of choroidal melanoma, where other treatments 75 with greater tumor control are not a feasible option. 


\section{INTRODUCTION:}

Photodynamic therapy (PDT) is used to treat a number of conditions in ocular oncology, including circumscribed choroidal ${ }^{1}$ and retinal capillary hemangiomas, ${ }^{2,3}$ choroidal metastasis, ${ }^{4}$ and vasoproliferative, ${ }^{5}$ conjunctival $^{6}$ and eyelid tumors. ${ }^{7}$ While choroidal melanoma is most commonly treated with radiotherapy, ${ }^{8}$ several groups have investigated the potential role of $\mathrm{PDT}^{9,10}$ given its minimally invasive nature and potential to preserve visual function, particularly in patients with small, posteriorly located choroidal melanomas.

Three primary mechanisms of action appear to be responsible for the anti-tumoral effects induced by PDT. On a cellular level, PDT generates cytotoxic intermediates causing direct tumor cell photodamage and resulting in tumor cell apoptosis. Immunologically, PDT activates NK-kB and other transcription factors which modulate and induce the local non-specific immune response. Finally, PDT causes destruction of the peritumoral vasculature, resulting in subsequent tumor cell necrosis. ${ }^{7,11-13}$

Tse et al reported encouraging results following the use of PDT with hematoporphyrin in 7 cases of uveal melanoma in $1984 .{ }^{14}$ Subsequently, several animal studies have evaluated the effect of PDT on both pigmented ${ }^{15-18}$ and amelanotic ${ }^{19,20}$ choroidal melanomas, with tumor regression seen in the majority of cases. Histologic examination of these tumors showed prominent vascular damage, ${ }^{15}$ tumor necrosis, ${ }^{15,16,20}$ and infiltration of mononuclear cells. ${ }^{17}$

Later study in humans suggested a correlation between the degree of tumor pigmentation and the amount of regression following PDT with haematoporphyrin, with lighter tumors responding better than heavily pigmented ones. ${ }^{21,22}$ Further to this, in 2005, Wachtlin et al treated 4 eyes with uveal melanoma destined for enucleation with PDT with verteporfin 2-3 days prior to surgery. Upon histopathological examination, they noted destructive effects within the two minimally pigmented tumors while the two heavily pigmented lesions had no appreciable necrosis. ${ }^{23}$

To date the options for treating posteriorly located choroidal melanoma while preserving vision are limited. Although greater pigmentation has previously been suggested as a risk factor for failure, the majority of choroidal melanomas fall into this category. We aimed to determine the role for PDT with verteporfin in this specific subset of patients in an effort to help answer one of the most common questions faced by ocular oncologists: is there a way to safely treat small, pigmented posteriorly located choroidal melanoma while preserving visual function? We have recently reported our 1- and 3-year results finding a tumor control rate of $80 \%{ }^{24}$ and $62 \%,{ }^{25}$ respectively. Herein, we provide the longer-term outcomes of primary PDT with verteporfin for small, pigmented, posterior uveal melanoma, from the same cohort. This study is a follow up study on the original series first published in $2017^{24}$ and later, the 3-year outcomes published in $2018 .{ }^{25}$

\section{METHODS:}


This retrospective study was approved by the Moorfields Eye Hospital clinical audit department (number 456), was conducted in accordance with the declaration of Helsinki and informed consent was obtained from all patients at the time of treatment. As this was a follow up study, the same inclusion criteria and treatment parameters were used as has been outlined in the previously described study methodology. ${ }^{24,25}$ Patients presenting to the London Ocular Oncology Service between April 2014 and December 2015 with AJCC $8^{\text {th }}$ edition T1a pigmented choroidal melanoma located in the posterior pole undergoing primary treatment with PDT with verteporfin were included if they had pigmentation of $\geq 50 \%$ of their surface area, thickness $<3 \mathrm{~mm}$ and either (a) documentation of recent growth or (b) $\geq 3$ risk factors for future growth. Risk factors included: Thickness $>2 \mathrm{~mm}$, presence of sub-retinal fluid, visual symptoms, presence of orange pigment and margin to the optic disc $\leq 3 \mathrm{~mm} .{ }^{26}$

Patient data, including sex, age, past ocular and medical history, visual acuity and tumor characteristics were collected from medical charts. Tumor response, complications and length of follow up, defined from the first PDT treatment to the last follow-up visit in clinic, was noted. Treatment failure was defined as growth in basal dimensions, thickness or both following PDT. All patients underwent systemic staging and were referred to a medical oncologist at the time of diagnosis. Subsequent metastatic surveillance was by way of abdominal ultrasounds every 6 months.

\section{Treatment protocol:}

Patients were treated following the protocol that has been previously described elsewhere ${ }^{24,25}$ (3 sessions of PDT 4-8 weeks apart with verteporfin [ $6 \mathrm{mg} / \mathrm{m}^{2}$ body surface area] light dose of $50 \mathrm{~J} / \mathrm{cm}^{2}$, power density of $600 \mathrm{~mW} / \mathrm{cm}^{2}$ and double duration [83s x 2] with a spot size titrated to cover the entire lesion). Concentric double duration spots were placed to ensure that the entire lesion and its margins were covered beyond the edge of the visible tumour. A light dose of $50 \mathrm{~J} / \mathrm{cm} 2$ rather than $100 \mathrm{~J} / \mathrm{cm} 2$ as chosen, as the latter has been shown to induce closure of deeper choroidal vessels ${ }^{27}$ and therefore, may be associated with a greater risk of visual morbidity. Double duration was selected in an effort to overcome the potential cytoprotective effects imparted by melanosomes, and three sessions were performed to increase the likelihood of inducing necrosis throughout the entire thickness of the lesion.

Statistical analysis:

Data are presented as mean \pm standard deviation (SD) when normally distributed or as median [interquartile range (IQR) and range], if not. Conventional descriptive statistics were used and all variables were assessed for normality using the Kolmogorov-Smirnov and ShapiroWilk test. When continuous variables were normally distributed, the students t-test was employed and the variance between groups was again checked using Levene's test for quality of variances. For non-normally distributed variables, the Mann-Whitney U test was used. Differences in categorical variables were analysed using Fisher's exact test with the FreemanHalton extension and Pearson Chi-Square. Kaplan-Meier survival estimate curves were used to predict treatment failure rate. A P-value of $<0.05$ was considered statistically significant. All data were analyzed using a commercially available software package (SPSS 2019®; IBM Corporation, Armonk, NY, USA).

\section{RESULTS:}


Twenty-six patients were included with a mean age of $62 \pm 14$ years. Fifteen $(58 \%)$ were female and the right and left eyes were affected with equal frequency. The median [IQR, range] tumor height was $1.3[0.7,0.9-2.7]$ and the mean $( \pm$ SD) largest basal dimension was $5.4 \pm 1.4$ $\mathrm{mm}$. As included cases were, by definition, posteriorly located, the median distance to the optic $\operatorname{disc}(2.0 \mathrm{~mm}[3.0 \mathrm{~mm} ; 0.0-9.0 \mathrm{~mm}])$ and fovea $(1.0 \mathrm{~mm}[2.5 \mathrm{~mm} ; 0.0-4.5 \mathrm{~mm}])$ were relatively small. Almost two-thirds of patients were symptomatic $(17 / 26 ; 65 \%)$. The majority of tumors were fully pigmented (19/26; 73\%), and had sub-retinal fluid $(23 / 26 ; 88 \%)$ and/or orange pigment $(23 / 26 ; 88 \%)$. (Table 1$)$

Pre and post treatment characteristics between failures and non-failures were compared. The two groups were similar with respect to age $(\mathrm{p}=0.417)$, gender $(\mathrm{p}=0.130)$, laterality $(p=0.695)$, initial LogMAR visual acuity $(p=0.734)$ and tumour height $(p=0.661)$ and largest basal dimension $(p=0.221)$. Cases with treatment failure had a shorter distance to the fovea (median [IQR, range]: $0.5 \mathrm{~mm}[1.3,0.0-4.0 \mathrm{~mm}])$ versus non-failures $(2.5 \mathrm{~mm}[2.8,0.5-4.5$ $\mathrm{mm}] ; \mathrm{p}=0.002)$. As may be expected, cases that were successfully treated with PDT had better final LogMAR visual acuity compared to cases that failed to maintain local tumour control following PDT (median [IQR, range]: 0.00 [0.14, $0.00-0.30]$ versus 0.50 [0.80, $0.00-2.00]$; $\mathrm{p}=0.002)$. (Table 2)

Overall, patients were followed for a median [IQR, range] of 49.5 [15.3, $7.0-66.0]$ months from first PDT to last follow up. Throughout this time period, 14/26 (54\%) of patients developed a local recurrence necessitating additional treatment. The most common pattern of recurrence was an isolated increase in basal dimensions $(9 / 14 ; 64 \%)$; however, 5 patients $(5 / 14$; $36 \%$ ) also had a concurrent increase in thickness. Five-year treatment-success calculated by Kaplan-Meier analysis was 38.4\% (Figure 1). The median time to failure was 20.0 months [20.5, $4.7-60.9$ months].

Two patients (patient 1 and 14) underwent a second treatment of PDT. Patient 14 developed an edge recurrence 21-months following the second PDT and received an additional course of PDT (total of 9 session). He has remained stable with a maximum tumor thickness of $0.7 \mathrm{~mm}$ at last follow up, 4.1 years after initial PDT. Patient 1 also had an edge recurrence necessitating plaque brachytherapy 6-months following the second course of PDT. This patient went on to developed a third recurrence 33 months following plaque brachytherapy and has recently undergone proton beam radiotherapy, 64 months following initial PDT.

A total of 8 patients underwent plaque brachytherapy as secondary treatment, however three of these patients (37\%) developed subsequent recurrences at 9-, 17- and 32- months following plaque. One of these patients was enucleated (patient 8) and two (patients 3 and 9) underwent proton beam radiotherapy. (Table 3). Histopathological analysis of the globe undergoing enucleation did not reveal any evidence of extraocular extension; however, there was also no evidence of tumour necrosis. Ten patients who are actively under ongoing close observation at our unit and have remained stable with no episodes of recurrence over a median follow up of 50.5 months $(15.5,14.0$ - 66.0 months) (Table 4, Figure 2) 
One patient (patient 5) died from metastatic prostate cancer 27 months after PDT and one patient (patient 19) died 7 months following PDT from unknown causes. Patient 8 was discharged for ongoing local follow up after undergoing enucleation 21 months following initial PDT. One patient (patient 11) was lost to follow up 14 months after PDT. To the best of our knowledge, none of the patients in this study has developed metastatic disease to date.

\section{DISCUSSION:}

While the decision to proceed with radiotherapy for medium size uveal melanoma tends to be a rather straightforward one, the timing of treatment for small, posteriorly located lesions is less widely agreed upon given that roughly half of these patients will have visual acuity $<20 / 200$ 5 years following iodine plaque brachytherapy. ${ }^{28}$ Although visual morbidity associated with ruthenium plaque brachytherapy may be less, if the posterior margin of the tumour is $<3 \mathrm{~mm}$ to the fovea, only $25 \%$ of patients maintain $20 / 40$ vision or better 3 years after treatment. ${ }^{29}$ In an effort to decrease the visual morbidity associated with treatment, several groups have investigated PDT for use in such cases.

A number of case reports ${ }^{30,31}$ and case series $^{9,10,21,22,24,25,32-34}$ have reported the effect of PDT on choroidal melanoma. (Table 5) In 2017, Fabian et al reported promising initial results in a prospective study of 15 patients with small, pigmented posterior pole choroidal melanoma. Following three sessions of PDT, tumor control was achieved in $80 \%$ of cases at a median follow up of 15 months. ${ }^{24}$ In a subsequent study however, the rate of local tumor control decreased to $62 \%$ at 29 months. ${ }^{25}$ In this report, we have found a local control rate of only $29 \%$ at 5 years.

This relatively low success rate is a stark contrast to the effectiveness of PDT with verteporfin for the treatment of other choroidal tumours, such as circumscribed choroidal hemangiomas $(\mathrm{CCH}) .{ }^{1,35,36}$ There are several potential explanations for these fundamentally different success rates. Photodynamic therapy has been shown to cause selective occlusion of the choriocapillaris due to the increased expression of low-density lipoprotein receptors in the endothelium. ${ }^{37}$ Hence, the primary mechanism of action of verteporfin PDT in cases of CCH appears to be thrombosis of angiomatous vessels, ${ }^{38}$ a theory supported by post-treatment fluorescein and indocyanine green angiography showing occlusive effects within the choroid. ${ }^{39}$ This contrasts to the proposed mechanisms of action in cases of choroidal melanoma, where PDT with verteporfin is thought to induce cellular damage via cytotoxic intermediates and activation of transcription factors. ${ }^{7,11-13}$ Moreover, although definitive evidence is lacking, some have hypothesized that verteporfin itself may play a direct role as an anticancer agent via its interaction with the Hippo pathway. ${ }^{40}$

\section{The effect of PDT in pigmented versus amelanotic uveal melanoma:}

Although the majority of animal studies examined the effect of PDT on cases of pigmented uveal melanoma ${ }^{15-18}$ several early human studies suggested an inverse correlation between the efficacy of PDT and the degree of tumor pigmentation. ${ }^{21-23}$ On a cellular level, this 
finding may be due to the cytoprotection provided by melanosomes in the RPE and uveal tract, ${ }^{41,42}$ with heavily pigmented tumors being more resilient in the face of oxidative stress.

In a series of 12 patients with amelanotic (83\%) or lightly pigmented (17\%) melanoma, Turkoglu et al found that primary PDT resulted in complete tumor regression in $67 \%$ at 5 years. ${ }^{10}$ O'Day et al recently published a series of 41 patients with amelanotic choroidal melanoma treated with up to 6 sessions of PDT at 3 month intervals. The majority $(88 \%)$ showed regression after initial PDT, however $51 \%$ required additional treatment over a mean follow up of 3.5 years. Similar to our current study, their time to recurrence was highly variable, ranging from 6 months to 5.5 years $^{9}$ (versus 4.7 months to 5.1 years in our study). (Table 5) However in contrast to the large series of amelanotic melanoma treated with PDT reported from Melbourne, Australia ${ }^{9}$, our publication included mainly pigmented tumours which may account for the $10 \%$ difference in local tumour control rates in the same time period. Interestingly, we found a higher rate of failure for lesions located close to the fovea $(p=0.002)$. One potential explanation for this finding is the anatomic changes that occur within the macula. The taller and narrower RPE cells in this area are more densely packed with melanin granules, theoretically imparting an enhanced level of cytoprotection, thus limiting the destructive effects of PDT.

\section{Histopathological findings following PDT:}

With respect to the histopathological effects inducted by PDT, Schlotzer-Schrehardt et al suggested that PDT has a dose related effect on choroidal and retinal structures, with $50 \mathrm{~J} / \mathrm{cm}^{2}$ resulting in selective occlusion of the choriocapillaris versus $100 \mathrm{~J} / \mathrm{cm}^{2}$ which also caused closure of deeper choroidal vessels and focal RPE alterations. ${ }^{27}$ Canal-Fontcuberta et al also noted closure of the superficial vasculature following a single session of PDT; however, 2 of the 5 eyes in this series showed viable melanoma cells with optic nerve and scleral invasion on histopathological examination. ${ }^{43}$ Of note, the one patient who underwent enucleation in our cohort did not have evidence of extrascleral extension on histopathology; however, there was no tumor necrosis noted.

The majority of the recurrences $(9 / 14 ; 64 \%)$ in the present study occurred in the form of isolated radial expansion, with little concurrent increase in apical thickness noted on ultrasound in most cases. This may be due to the overlying superficial fibrosis induced by PDT, potentially leaving residual tumor cells at the base of the lesion free to grow posteriorly and laterally along the path of least resistance. ${ }^{43}$

A similar phenomenon has been suggested to occur following TTT, with most recurrences presenting as lateral extensions with minimal increases in thickness. ${ }^{44}$ In a series of 357 consecutive patients receiving primary TTT for choroidal melanoma, 10 patients $(2.8 \%)$ eventually required enucleation. Compared to cases of choroidal melanoma undergoing primary enucleation, those that are enucleated following failed primarily treatment with TTT have a much higher incidence of extra-scleral extension ( $8 \%{ }^{45}$ versus $40-71 \%,{ }^{44,46}$ respectively). It remains unclear whether or not this risk holds true for patients undergoing primary treatment with PDT given the small cumulative number of cases requiring enucleation reported in the literature. 
It is likely that the small tumours included in this study were melanomas rather than nevi, as documentation of growth was seen in $42 \%$ and there was the presence of $\geq 3$ risk factors for future growth in all cases, especially lipofuscin. Most ocular oncologists would consider these to be reasonable indicators for offering treatment for choroidal melanoma. Therefore, this cohort is representative of the real-world population with small, posteriorly located choroidal melanocytic tumours who would be offered treatment as choroidal melanoma. Although correlation of PDT response with cytopathologic or cytogenetic results would be of interest, the small size and posterior location of these tumors makes this difficult to achieve. Although in the majority of instances intraocular biopsy can be carried out uneventfully, ${ }^{47}$ there is a small risk of visual complications, an unwanted sequela when the motivation for these patients was to preserve their vision.

\section{Use of PDT as adjuvant and neo-adjuvant treatment in uveal melanoma:}

Photodynamic therapy has also been reported as an adjuvant and neo-adjuvant treatment in combination with plaque brachytherapy. Tuncer et al reported a case of a $6.5 \mathrm{~mm}$ amelanotic choroidal melanoma that responded poorly to plaque brachytherapy but showed dramatic regression following three sessions of PDT. ${ }^{48}$ Barbazetto et al similarly found PDT useful as a salvage treatment in four patients with recurrences following plaque brachytherapy and TTT. ${ }^{49}$ In a case series of 26 patients, Blasi et al suggested that pre-radiotherapy PDT can reduced tumor thickness in the majority of cases (73.4\%) allowing for a smaller radiation dose and subsequently less effect on visual function without compromising disease control..$^{50}$

\section{Effect of PDT on future radiotherapy and risk of systemic metastasis:}

Although some authors have advocated the use of PDT in a neo-adjuvant fashion proceeding plaque brachytherapy, finding no difference in recurrence rates at 2 years, ${ }^{50}$ we found a relatively high rate of failure following secondary plaque $(3 / 8 ; 37 \%)$. O'Day et al reported similar findings with 2 of $9(22 \%)$ patients undergoing secondary plaque later developing recurrent disease requiring enucleation. They hypothesized that the tumoral ischemia induced by PDT could theoretically reduce radiotoxicity, accounting for a higher than typical rate of local recurrence following plaque brachytherapy. ${ }^{9}$ Although our ability to discern whether or not there is a statistically significant increase in the risk of failure following secondary plaque radiotherapy, this potential consequence should be carefully weighed prior to proceeding with primary PDT, particularly for pigmented lesions.

Plaque and proton beam radiotherapy have excellent local tumor control rates, with 89.7$96.8 \%$ of patients exhibiting tumor control at 5 years. ${ }^{51,52}$ Although short term local tumor control following primary treatment with PDT is encouraging $(80 \% \text { at } 1 \text { year })^{24}$ this appears to decrease over time to only $38 \%$ by five years. While exceptions to the rule may arise in certain clinical scenarios, PDT with verteporfin is not recommended for primary treatment of choroidal melanoma in the majority of instances. Local tumor control is an important outcome metric, as some have found tumor recurrence to be independently associated with an increased risk of metastasis and tumor-related death. ${ }^{52}$ Although no patient in our study, and only one patient in the published literature, ${ }^{9}$ developed metastatic disease following primary treatment with PDT, it is likely that our follow up time is not yet long enough to adequately evaluate this outcome, particularly given the small size of tumors included. 
The notion of a local laser treatment to activate an appropriately sensitised substrate for small melanomas to preserve vision is an attractive one. This principle is being applied to the Aura biosciences compound (AU-011), which is injected into the vitreous cavity and then activated by laser. ${ }^{53}$ It is hoped that such an approach will be superior to verteporfin PDT, in the setting of treating small melanomas while at the same time trying to preserve vision.

In summary, due to the substantial risk of recurrence, primary treatment with verteporfin PDT for small pigmented choroidal melanoma is not recommended in the majority of cases. As rare exceptions to this recommendation will arise in the real-world setting, in the instance that treatment with PDT is performed, close long-term follow up is of paramount importance given the highly variable time to recurrence. As most recurrences after PDT tend to occur along the tumor edges, often with minimal increase in thickness, close monitoring with serial fundus photography and enhanced depth imaging OCT is of paramount importance in detecting recurrence early. (Figure 3) The relatively high rate of recurrence following plaque brachytherapy in both our study and the series published by O'Day et al requires further investigation, and should be taken into account when counseling a patient for primary treatment with verteporfin PDT. However, this treatment strategy allows for maintenance of excellent vision, supporting a possible role for use of verteporfin PDT, particularly in monocular patients or those with other co-morbidities. 
368 Acknowledgements: The research was supported by the National Institute for Health Research 369 (NIHR) Biomedical Research Centre based at Moorfields Eye Hospital NHS Foundation Trust 370 and UCL Institute of Ophthalmology. The views expressed are those of the author(s) and not 371 necessarily those of the NHS, the NIHR or the Department of Health. 


\section{REFERENCES:}

1. Papastefanou VP, Plowman PN, Reich E, et al. Analysis of Long-term Outcomes of Radiotherapy and Verteporfin Photodynamic Therapy for Circumscribed Choroidal Hemangioma. Ophthalmol Retina. 2018;2(8):842-857.

2. Papastefanou VP, Pilli S, Stinghe A, Lotery AJ, Cohen VM. Photodynamic therapy for retinal capillary hemangioma. Eye (Lond). 2013;27(3):438-442.

3. Schmidt-Erfurth UM, Kusserow C, Barbazetto IA, Laqua H. Benefits and complications of photodynamic therapy of papillary capillary hemangiomas. Ophthalmology. 2002;109(7):1256-1266.

4. Ghodasra DH, Demirci H. Photodynamic Therapy for Choroidal Metastasis. Am J Ophthalmol. 2016;161:104-109 e101-102.

5. Blasi MA, Scupola A, Tiberti AC, Sasso P, Balestrazzi E. Photodynamic therapy for vasoproliferative retinal tumors. Retina. 2006;26(4):404-409.

6. Barbazetto IA, Lee TC, Abramson DH. Treatment of conjunctival squamous cell carcinoma with photodynamic therapy. Am J Ophthalmol. 2004;138(2):183-189.

7. Cerman E, Cekic O. Clinical use of photodynamic therapy in ocular tumors. Surv Ophthalmol. 2015;60(6):557-574.

8. Shields JA, Shields CL. Management of posterior uveal melanoma: past, present, and future: the 2014 Charles L. Schepens lecture. Ophthalmology. 2015;122(2):414-428.

9. O'Day RF, Pejnovic TM, Isaacs T, Muecke JS, Glasson WJ, Campbell WG. Australian and New Zealand Study of Photodynamic Therapy in Choroidal Amelanotic Melanoma. Retina. 2019.

10. Turkoglu EB, Pointdujour-Lim R, Mashayekhi A, Shields CL. Photodynamic Therapy as Primary Treatment for Small Choroidal Melanoma. Retina. 2019;39(7):1319-1325.

11. Nowis D, Makowski M, Stoklosa T, Legat M, Issat T, Golab J. Direct tumor damage mechanisms of photodynamic therapy. Acta Biochim Pol. 2005;52(2):339-352.

12. Gomer CJ. Preclinical examination of first and second generation photosensitizers used in photodynamic therapy. Photochem Photobiol. 1991;54(6):1093-1107.

13. Dougherty TJ. Photosensitization of malignant tumors. Semin Surg Oncol. 1986;2(1):2437.

14. Tse DT, Dutton JJ, Weingeist TA, Hermsen VM, Kersten RC. Hematoporphyrin photoradiation therapy for intraocular and orbital malignant melanoma. Arch Ophthalmol. 1984;102(6):833-838.

15. Gonzalez VH, Hu LK, Theodossiadis PG, Flotte TJ, Gragoudas ES, Young LH. Photodynamic therapy of pigmented choroidal melanomas. Invest Ophthalmol Vis Sci. 1995;36(5):871-878.

16. Kim RY, Hu LK, Foster BS, Gragoudas ES, Young LH. Photodynamic therapy of pigmented choroidal melanomas of greater than 3-mm thickness. Ophthalmology. 1996;103(12):2029-2036.

17. Young LH, Howard MA, Hu LK, Kim RY, Gragoudas ES. Photodynamic therapy of pigmented choroidal melanomas using a liposomal preparation of benzoporphyrin derivative. Arch Ophthalmol. 1996;114(2):186-192. 
18. Hu L, Wu X, Song Y, Young LH, Gragoudas ES. [Photodynamic therapy of pigmented choroidal melanomas in rabbits]. Zhonghua Yan Ke Za Zhi. 2002;38(8):491-494.

19. Rapozzi V, Zorzet S, Zacchigna M, Drioli S, Xodo LE. The PDT activity of free and pegylated pheophorbide a against an amelanotic melanoma transplanted in C57/BL6 mice. Invest New Drugs. 2013;31(1):192-199.

20. Schmidt-Erfurth U, Bauman W, Gragoudas E, et al. Photodynamic therapy of experimental choroidal melanoma using lipoprotein-delivered benzoporphyrin. Ophthalmology. 1994;101(1):89-99.

21. Favilla I, Favilla ML, Gosbell AD, et al. Photodynamic therapy: a 5-year study of its effectiveness in the treatment of posterior uveal melanoma, and evaluation of haematoporphyrin uptake and photocytotoxicity of melanoma cells in tissue culture. Melanoma Res. 1995;5(5):355-364.

22. Favilla I, Barry WR, Gosbell A, Ellims P, Burgess F. Phototherapy of posterior uveal melanomas. Br J Ophthalmol. 1991;75(12):718-721.

23. Wachtlin J, Bechrakis NE, Foerster $\mathrm{MH}$. [Photodynamic therapy with verteporfin for uveal melanoma]. Ophthalmologe. 2005;102(3):241-246.

24. Fabian ID, Stacey AW, Papastefanou V, et al. Primary photodynamic therapy with verteporfin for small pigmented posterior pole choroidal melanoma. Eye (Lond). 2017;31(4):519-528.

25. Fabian ID, Stacey AW, Harby LA, Arora AK, Sagoo MS, Cohen VML. Primary photodynamic therapy with verteporfin for pigmented posterior pole cT1a choroidal melanoma: a 3-year retrospective analysis. Br J Ophthalmol. 2018;102(12):1705-1710.

26. Shields CL, Cater J, Shields JA, Singh AD, Santos MC, Carvalho C. Combination of clinical factors predictive of growth of small choroidal melanocytic tumors. Arch Ophthalmol. 2000;118(3):360-364.

27. Schlotzer-Schrehardt U, Viestenz A, Naumann GO, Laqua H, Michels S, Schmidt-Erfurth $U$. Dose-related structural effects of photodynamic therapy on choroidal and retinal structures of human eyes. Graefes Arch Clin Exp Ophthalmol. 2002;240(9):748-757.

28. Sagoo MS, Shields CL, Emrich J, Mashayekhi A, Komarnicky L, Shields JA. Plaque radiotherapy for juxtapapillary choroidal melanoma: treatment complications and visual outcomes in 650 consecutive cases. JAMA Ophthalmol. 2014;132(6):697-702.

29. Russo A, Laguardia M, Damato B. Eccentric ruthenium plaque radiotherapy of posterior choroidal melanoma. Graefes Arch Clin Exp Ophthalmol. 2012;250(10):1533-1540.

30. Donaldson MJ, Lim L, Harper CA, Mackenzie J, W GC. Primary treatment of choroidal amelanotic melanoma with photodynamic therapy. Clin Exp Ophthalmol. 2005;33(5):548-549.

31. Soucek $P$, Cihelkova I. Photodynamic therapy with verteporfin in subfoveal amelanotic choroidal melanoma (A controlled case). Neuro Endocrinol Lett. 2006;27(1-2):145-148.

32. Jmor F, Hussain RN, Damato BE, Heimann H. Photodynamic therapy as initial treatment for small choroidal melanomas. Photodiagnosis Photodyn Ther. 2017;20:175-181.

33. Rundle P. Treatment of posterior uveal melanoma with multi-dose photodynamic therapy. Br J Ophthalmol. 2014;98(4):494-497.

34. Campbell WG, Pejnovic TM. Treatment of amelanotic choroidal melanoma with photodynamic therapy. Retina. 2012;32(7):1356-1362. 
35. Di Nicola M, Williams BK, Jr., Srinivasan A, et al. Photodynamic Therapy (PDT) for Circumscribed Choroidal Hemangioma in 79 Consecutive Patients: Comparative Analysis of Factors Predictive of Visual Outcome. Ophthalmol Retina. 2020.

36. Shields CL, Dalvin LA, Lim LS, et al. Circumscribed Choroidal Hemangioma: Visual Outcome in the Pre-Photodynamic Therapy Era versus Photodynamic Therapy Era in 458 Cases. Ophthalmol Retina. 2020;4(1):100-110.

37. Schmidt-Erfurth U, Hasan T, Gragoudas E, Michaud N, Flotte TJ, Birngruber R. Vascular targeting in photodynamic occlusion of subretinal vessels. Ophthalmology. 1994;101(12):1953-1961.

38. Schmidt-Erfurth UM, Michels S, Kusserow C, Jurklies B, Augustin AJ. Photodynamic therapy for symptomatic choroidal hemangioma: visual and anatomic results. Ophthalmology. 2002;109(12):2284-2294.

39. Schmidt-Erfurth $U$, Niemeyer M, Geitzenauer W, Michels S. Time course and morphology of vascular effects associated with photodynamic therapy. Ophthalmology. 2005;112(12):2061-2069.

40. Harvey KF, Zhang X, Thomas DM. The Hippo pathway and human cancer. Nat Rev Cancer. 2013;13(4):246-257.

41. Hu DN, Simon JD, Sarna T. Role of ocular melanin in ophthalmic physiology and pathology. Photochem Photobiol. 2008;84(3):639-644.

42. Burke JM, Kaczara P, Skumatz CM, Zareba M, Raciti MW, Sarna T. Dynamic analyses reveal cytoprotection by RPE melanosomes against non-photic stress. Mol Vis. 2011;17:2864-2877.

43. Canal-Fontcuberta I, Salomao DR, Robertson D, et al. Clinical and histopathologic findings after photodynamic therapy of choroidal melanoma. Retina. 2012;32(5):942948.

44. Zaldivar RA, Aaberg TM, Sternberg P, Jr., Waldron R, Grossniklaus HE. Clinicopathologic findings in choroidal melanomas after failed transpupillary thermotherapy. Am J Ophthalmol. 2003;135(5):657-663.

45. Histopathologic characteristics of uveal melanomas in eyes enucleated from the Collaborative Ocular Melanoma Study. COMS report no. 6. Am J Ophthalmol. 1998;125(6):745-766.

46. Singh AD, Eagle RC, Jr., Shields CL, Shields JA. Clinicopathologic reports, case reports, and small case series: enucleation following transpupillary thermotherapy of choroidal melanoma: clinicopathologic correlations. Arch Ophthalmol. 2003;121(3):397-400.

47. Seider MI, Berry DE, Schefler AC, et al. Multi-center analysis of intraocular biopsy technique and outcomes for uveal melanoma: Ocular Oncology Study Consortium report 4. Graefes Arch Clin Exp Ophthalmol. 2020;258(2):427-435.

48. Tuncer S, Kir N, Shields CL. Dramatic regression of amelanotic choroidal melanoma with PDT following poor response to brachytherapy. Ophthalmic Surg Lasers Imaging. 2012;43(3):e38-40.

49. Barbazetto IA, Lee TC, Rollins IS, Chang S, Abramson DH. Treatment of choroidal melanoma using photodynamic therapy. Am J Ophthalmol. 2003;135(6):898-899. 
501 50. Blasi MA, Laguardia M, Tagliaferri L, et al. BRACHYTHERAPY ALONE OR WITH NEOADJUVANT PHOTODYNAMIC THERAPY FOR AMELANOTIC CHOROIDAL MELANOMA:

51. Jampol LM, Moy CS, Murray TG, et al. The COMS randomized trial of iodine 125 brachytherapy for choroidal melanoma: IV. Local treatment failure and enucleation in the first 5 years after brachytherapy. COMS report no. 19. Ophthalmology. 2002;109(12):2197-2206.

52. Gragoudas ES, Lane AM, Munzenrider J, Egan KM, Li W. Long-term risk of local failure after proton therapy for choroidal/ciliary body melanoma. Trans Am Ophthalmol Soc. 2002;100:43-48; discussion 48-49.

53. Kines RC, Varsavsky I, Choudhary S, et al. An Infrared Dye-Conjugated Virus-like Particle for the Treatment of Primary Uveal Melanoma. Mol Cancer Ther. 2018;17(2):565-574. 


\section{TABLE and FIGURE LEGENDS:}

Table 1. Demographic and baseline clinical features of 23 patients with cT1 a choroidal melanoma undergoing primary treatment with photodynamic therapy

Table 2. Comparison of pre- and post-treatment characteristics between failure and non-failures.

Table 3. Long term outcomes of 23 patients with small choroidal melanomas undergoing primary treatment with photodynamic therapy.

Table 4. Outcome characteristics of the 7 patients with ongoing follow up and no recurrence following PDT

Table 5. Summary of selected case series evaluating the use of PDT with verteporfin for treatment of choroidal melanoma

Figure 1. Kaplan-Meier estimate for treatment-success following PDT with verteporfin.

Figure 2. A 75-year-old man (patient 22) presented with (A) a lightly pigmented choroidal melanoma with (B) shallow sub-retinal fluid noted on OCT. Forty two months later he remains stable with (C) chorioretinal scaring and atrophy overlying the lesion and (D) no evidence of residual choroidal thickening on OCT.

Figure 3. A 56-year-old male (patient 14) presented with a small choroidal melanoma in May 2015. (A and B) Colour fundus photographs show a pigmented choroidal lesion with lipofuscin, highlighted on autofluorescence. (C) OCT through the lesion confirms the presence of subretinal fluid. (D) Six months following primary treatment with three sessions of PDT, atrophy and chorioretinal scarring are aparent and (E and F) enhanced depth imaging OCT through the central (white star/arrow) and superior margin (black star/arrow) of the lesion confirm regression. (G) While the basal dimensions noted on fundus photographs 14 months later appear relatively unchanged, ( $\mathrm{H}$ and $\mathrm{I}$ ) a subtle thickening of the central portion of the lesion (white star/arrow) and a more marked thickening of the superior border (black star/arrow) noted on EDI-OCT allowed for an early detection of recurrence. 
549 Table 1. Demographic and baseline clinical features of 26 patients with cT1a choroidal 550 melanoma undergoing primary treatment with photodynamic therapy

\begin{tabular}{|c|c|}
\hline $\begin{array}{l}\text { Age (years) } \\
\quad(\text { Mean } \pm \text { SD, Median }[\mathrm{IQR}, \text { range]) }\end{array}$ & $62 \pm 14$ \\
\hline \multicolumn{2}{|l|}{ Gender $(\%)$} \\
\hline Female & $15(58)$ \\
\hline Male & $11(42)$ \\
\hline \multicolumn{2}{|l|}{ Laterality $(\%)$} \\
\hline Right & $13(50)$ \\
\hline Left & $13(50)$ \\
\hline \multicolumn{2}{|l|}{ Initial LogMAR affected eye } \\
\hline (Median [IQR, range]) & $0.18[0.3,-0.08-0.50]$ \\
\hline \multicolumn{2}{|l|}{ Tumor dimensions (mm) } \\
\hline Height (Median [IQR, range]) & $1.3[0.7 ; 0.9-2.7]$ \\
\hline Largest basal dimension (Mean $\pm \mathrm{SD}$, range) & $5.4 \pm 1.4,3.0-8.9$ \\
\hline \multicolumn{2}{|l|}{ Distance of tumor from (mm) } \\
\hline Optic Disc (Median [IQR, range]) & $2.0[3.0 ; 0.0-9.0]$ \\
\hline Fovea (Median [IQR, range]) & $1.0[2.5 ; 0.0-4.5]$ \\
\hline \multicolumn{2}{|l|}{ Presence of subretinal fluid } \\
\hline General $(\%)$ & $23(88)$ \\
\hline Foveal $(\%)$ & $14(54)$ \\
\hline Symptomatic (\%) & $17(65)$ \\
\hline Orange pigment & $23(88)$ \\
\hline \multicolumn{2}{|l|}{ Pigmentation } \\
\hline Complete & $19(73)$ \\
\hline Partial & $7(27)$ \\
\hline Amelanotic & $0(0)$ \\
\hline \multicolumn{2}{|l|}{ Diagnosis } \\
\hline Diagnosed as melanoma on first visit & $15(58)$ \\
\hline Transformed choroidal nevus & $11(42)$ \\
\hline \multicolumn{2}{|l|}{ Time to transformation (months) } \\
\hline$($ Mean $\pm \mathrm{SD}$, Median $[\mathrm{IQR}$, range $])$ & $67 \pm 55,60[69,3-190]$ \\
\hline
\end{tabular}


Table 2. Comparison of pre- and post-treatment characteristics between failure and non-failures.

557

\begin{tabular}{lccc}
\hline & Failure $(\mathrm{n}=14)$ & Non-failure $(\mathrm{n}=12)$ & $\mathrm{P}$-value \\
\hline Age & $64 \pm 16$ & $59 \pm 11$ & $0.417^{*}$ \\
\hline Gender & & & $0.130^{\dagger}$ \\
Male & $8(57)$ & $3(25)$ & \\
Female & $6(43)$ & $9(75)$ & $0.695^{\dagger}$ \\
\hline Laterality & & & $5(42)$ \\
Right & $8(57)$ & $7(58)$ &
\end{tabular}

\begin{tabular}{|c|c|c|c|}
\hline Initial LogMAR visual acuity (Median [IQR, range]) & $0.18[0.30,-0.08-0.50]$ & $0.18[0.28,-0.08-0.30]$ & 0.734 \\
\hline \multicolumn{4}{|l|}{ Tumor dimensions (mm) } \\
\hline Height (Median [IQR, range]) & $1.3[1.0,0.9-2.7]$ & $1.3[0.5,0.9-1.8]$ & $0.661^{*}$ \\
\hline Largest basal dimension (Mean \pm SD) & $5.8 \pm 1.7$ & $5.0 \pm 0.9$ & $0.221^{*}$ \\
\hline \multicolumn{4}{|l|}{ Distance of tumor from (mm) } \\
\hline Optic Disc (Median [IQR, range]) & $1.8[2.6,0.0-4.5]$ & $2.0[3.4,0.0-9.0]$ & $0.694^{\ddagger}$ \\
\hline Fovea (Median [IQR, range]) & $0.5[1.3,0.0-4.0]$ & $2.5[2.8,0.5-4.5]$ & $0.002^{\ddagger}$ \\
\hline \multicolumn{4}{|l|}{ Sub-retinal fluid at initial exam } \\
\hline General & $14(100)$ & $9(75)$ & $0.085^{\dagger}$ \\
\hline Sub-foveal & $9(64)$ & $5(42)$ & $0.431^{\dagger}$ \\
\hline Symptomatic (\%) & $10(71)$ & $7(58)$ & $0.683^{\dagger}$ \\
\hline Orange pigment & $13(93)$ & $10(83)$ & $0.580^{\dagger}$ \\
\hline Pigmentation & & & $0.838^{\S}$ \\
\hline Complete & $10(71)$ & $9(75)$ & \\
\hline Partial & $4(29)$ & $3(25)$ & \\
\hline Amelanotic & $0(0)$ & $0(0)$ & \\
\hline Final LogMAR visual acuity (Median [IQR, range]) & $0.50[0.80,0.00-2.00]$ & $0.00[0.14,0.00-0.30]$ & $\mathbf{0 . 0 0 2}$ \\
\hline Total follow up (months) (Median [IQR, range]) & $49.5[13.8,7.0-63.0]$ & $50.5[15.5,14.0-66.0]$ & $0.918^{\ddagger}$ \\
\hline
\end{tabular}

${ }^{*}$ students t-test

$559 \dagger$ Fishers exact test

$560 \quad$ Mann-Whitney U test

$561 \S$ Chi-square test 
564 Table 3. Long term outcomes of 26 patients with small choroidal melanomas undergoing primary 565 treatment with photodynamic therapy.

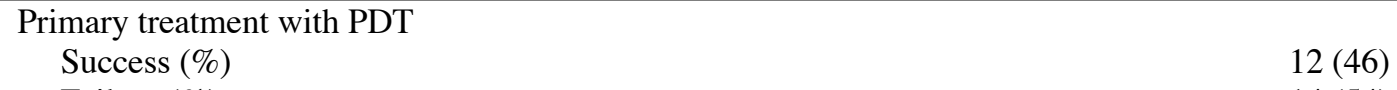

Failure (\%)

Time to failure

9-, 17- and 32- months

Proton beam radiotherapy

Success $(\%)$

$4(100)$

Failure (\%)

$0(0)$

\begin{tabular}{cc}
\hline Tertiary treatment & $1 *$ \\
PDT & $1(100)$ \\
Success (\%) & $0(0 \%)$ \\
Failure (\%) & 1 \\
Ruthenium plaque brachytherapy & $0(0)$ \\
Success (\%) & $1(100)^{* *}$ \\
Failure (\%) & 33 -month \\
Time to failure & \\
& 2 \\
Proton beam radiotherapy & $2(100)$ \\
Success (\%) & $0(0)$ \\
Failure (\%) &
\end{tabular}

Enucleation

1

$567 *$ This patient underwent a total of 3 sessions of PDT and has remained stable 4.1 years following initial PDT

$568 * *$ this patient underwent proton beam radiotherapy as a quaternary treatment 64 months following initial PDT 
571 Table 4. Outcome characteristics of the 10 patients with ongoing follow up and no recurrence 572 following PDT

573

\begin{tabular}{|c|c|c|c|c|c|c|c|c|c|}
\hline $\begin{array}{l}\text { Study } \\
\text { Number }\end{array}$ & Age & Diagnosis & Pigmentation & $\begin{array}{l}\text { Thickness } \\
\text { pre- } \\
\text { treatment } \\
(\mathrm{mm})\end{array}$ & $\begin{array}{l}\text { Thickness } \\
\text { at last } \\
\text { follow up } \\
(\mathrm{mm})\end{array}$ & $\begin{array}{l}\text { SRF } \\
\text { involving } \\
\text { the fovea } \\
\text { and/or } \\
\text { lesion at } \\
\text { last follow } \\
\text { up }\end{array}$ & Systemic status & $\begin{array}{l}\text { LogMAR } \\
\text { at last } \\
\text { follow up }\end{array}$ & $\begin{array}{l}\text { Total } \\
\text { follow up } \\
\text { (months) }\end{array}$ \\
\hline 2 & 51 & $\begin{array}{l}\text { Transformed } \\
\text { nevus }\end{array}$ & Complete & 0.9 & 0.5 & No & $\begin{array}{l}\text { Alive, no } \\
\text { metastasis }\end{array}$ & 0 & 66 \\
\hline 6 & 56 & $\begin{array}{l}\text { Transformed } \\
\text { nevus }\end{array}$ & Partial & 1.5 & 1.1 & Yes & $\begin{array}{l}\text { Alive, no } \\
\text { metastasis }\end{array}$ & 0 & 58 \\
\hline 13 & 58 & $\begin{array}{l}\text { Transformed } \\
\text { nevus }\end{array}$ & Complete & 1.4 & 1.5 & No & $\begin{array}{l}\text { Alive, no } \\
\text { metastasis }\end{array}$ & 0 & 54 \\
\hline 17 & 54 & Melanoma & Complete & 1.1 & 1.2 & No & $\begin{array}{l}\text { Alive, no } \\
\text { metastasis }\end{array}$ & 0 & 44 \\
\hline 20 & 50 & Melanoma & Complete & 1.7 & 0.4 & No & $\begin{array}{l}\text { Alive, no } \\
\text { metastasis }\end{array}$ & 0 & 47 \\
\hline 21 & 65 & Melanoma & Partial & 1.6 & 0.8 & No & $\begin{array}{l}\text { Alive, no } \\
\text { metastasis }\end{array}$ & 0.2 & 45 \\
\hline 22 & 75 & $\begin{array}{l}\text { Transformed } \\
\text { nevus }\end{array}$ & Complete & 1.8 & 0.8 & No & $\begin{array}{l}\text { Alive, no } \\
\text { metastasis }\end{array}$ & 0 & 42 \\
\hline 24 & 69 & Melanoma & Partial & 1.1 & 0.7 & No & $\begin{array}{l}\text { Alive, no } \\
\text { metastasis }\end{array}$ & 0.2 & 64 \\
\hline 25 & 38 & $\begin{array}{l}\text { Transformed } \\
\text { nevus }\end{array}$ & Complete & 1.7 & 0.8 & No & $\begin{array}{l}\text { Alive, no } \\
\text { metastasis }\end{array}$ & 0.0 & 54 \\
\hline 26 & 55 & Melanoma & Partial & 1.2 & 0.8 & No & $\begin{array}{l}\text { Alive, no } \\
\text { metastasis }\end{array}$ & 0.0 & 58 \\
\hline
\end{tabular}


577 Figure 1

578

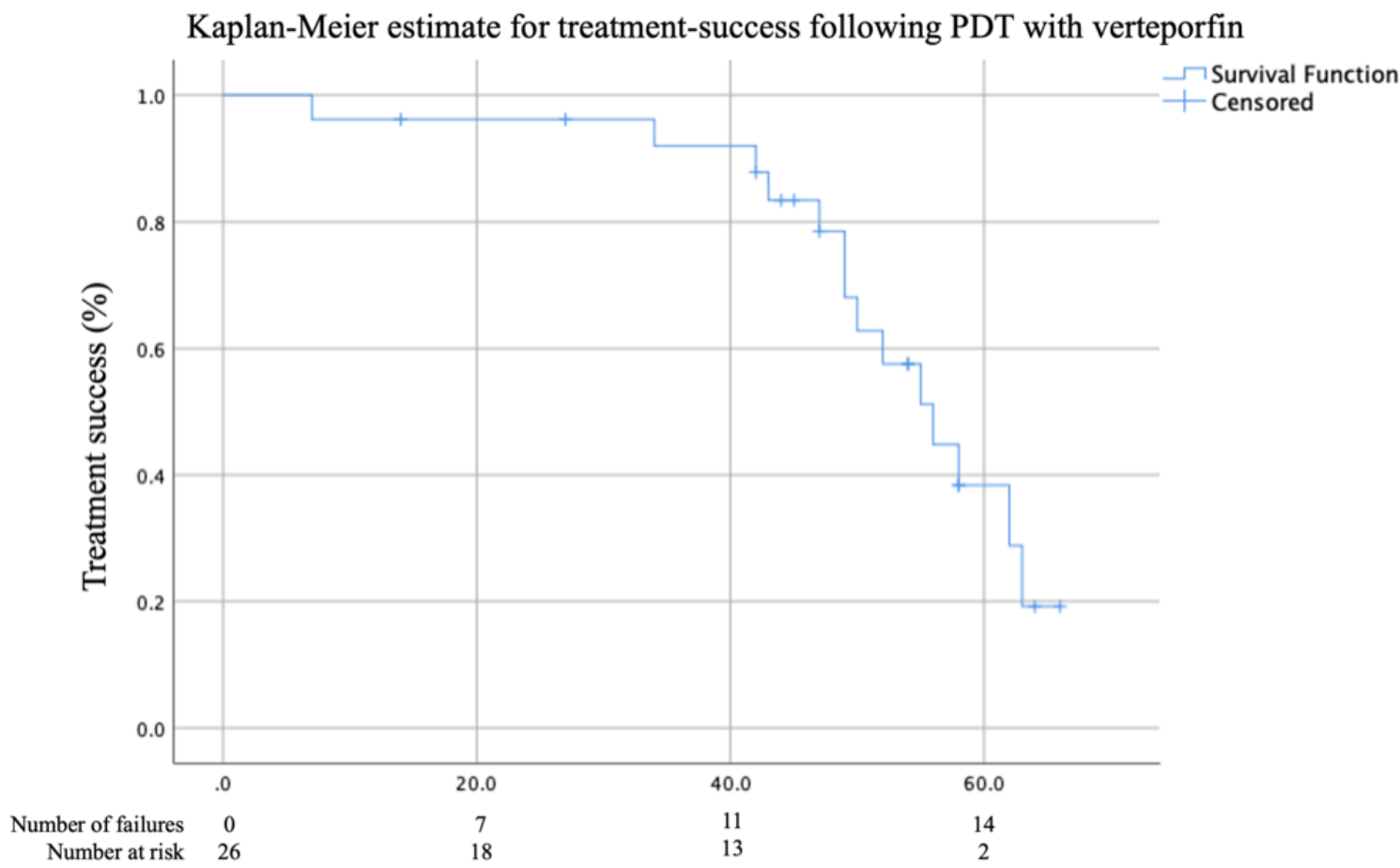

Time following treatment with PDT (months) 
581 Figure 2

582

583

584

585

586

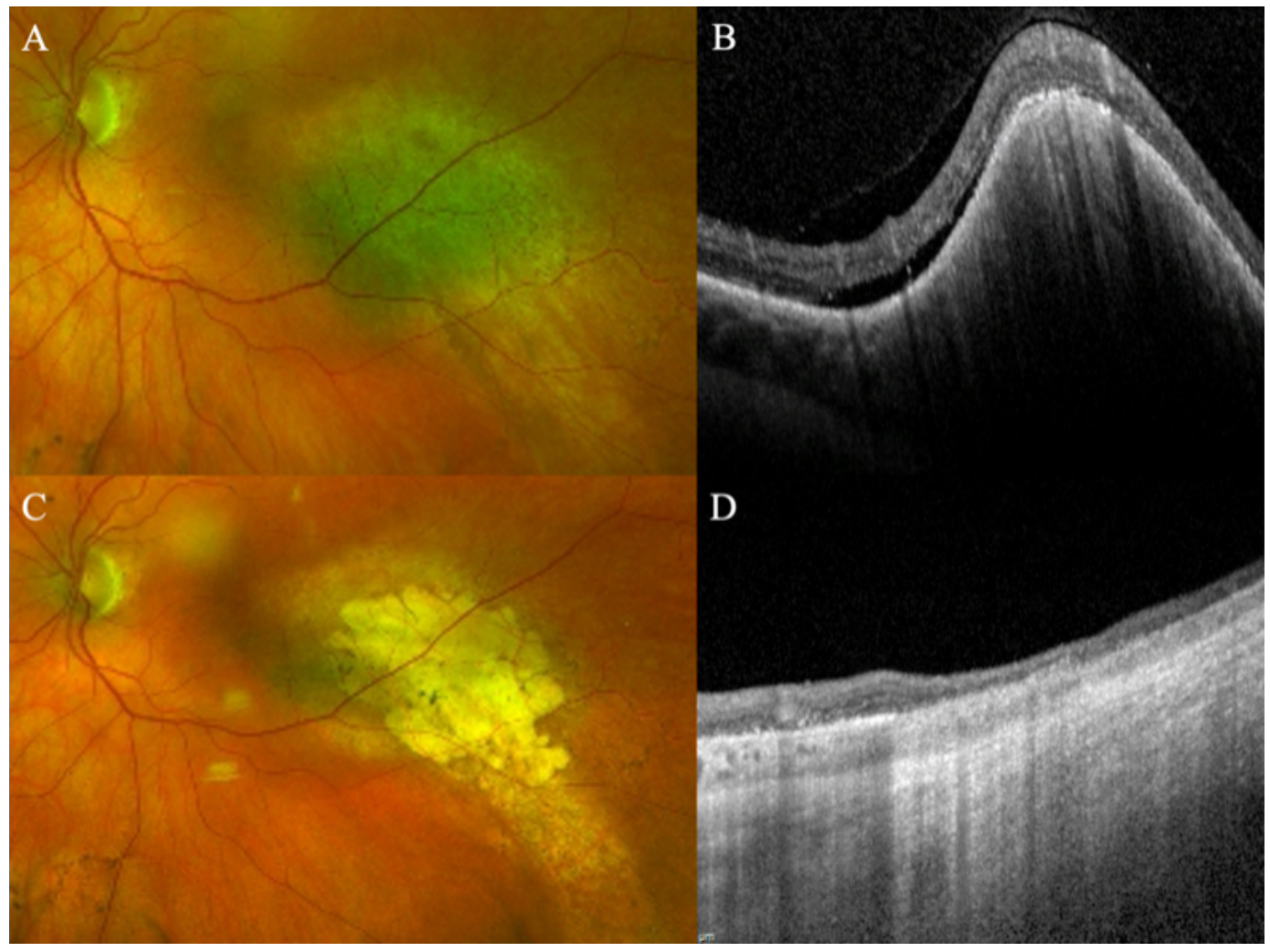


587 Figure 3

588
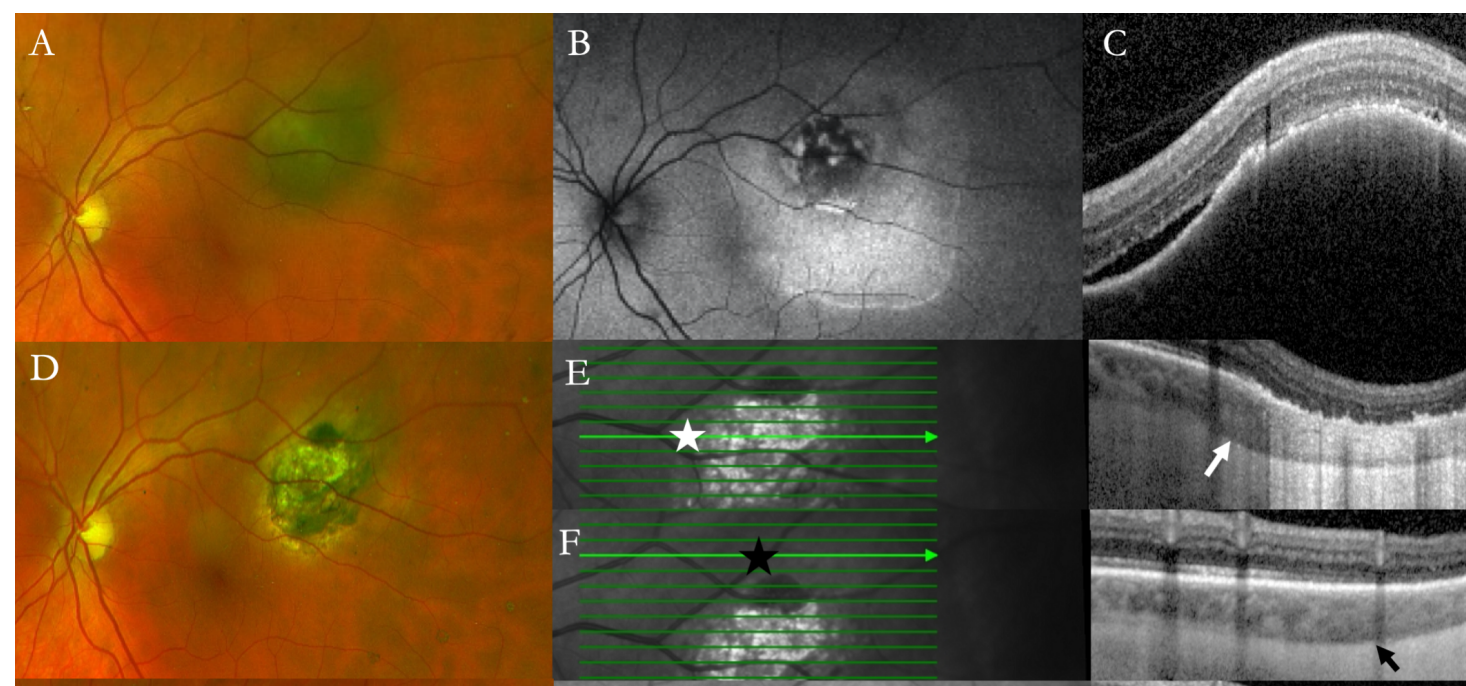

G
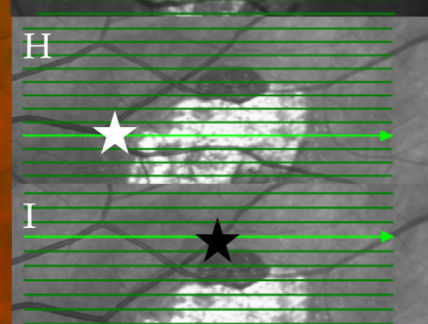